Ger J Exerc Sport Res 2018 • 48:245-251 https://doi.org/10.1007/s12662-018-0510-7 Received: 11 September 2017

Accepted: 20 March 2018

Published online: 23 April 2018

(c) The Author(s) 2018.

CrossMark

\section{Introduction}

In addition to the technical and tactical training, superior physical development, including strength, endurance (stamina), and agility, is of great importance in soccer (Hoff, 2005). Thus, the properties of the muscle-tendon unit (MTU) play a central role in the performance of a player. Adaptations in the MTU due to training have been reported to be specific in different types of sports. In a study of track and field athletics, Arampatzis, Karamanidis, Morey-Klapsing, De Monte, and Stafilidis (2007) compared endurance athletes with sprinters and found that the sprinters had significantly higher maximum voluntary contraction (MVC) torques and (active) tendon stiffness than the endurance athletes. Additionally, specific adaptations of the MTU have also been reported in endurance athletes: Several studies found structural adaptations due to endurance training habits in the muscle cross sectional area (Stenroth et al., 2015), fascicle length (Oda et al., 2013), tendon length (Sano et al., 2013), and tendon stiffness (Oda et al., 2013; Kunimasa et al., 2015).

Even within a specific type of sport, e.g., soccer, the requirements for athletes in different playing positions may differ substantially, which might lead to different MTU adaptations. Faria, Gabriel, Abrantes, Wood, and Moreira (2013) investigated MVC torque and muscletendon stiffness in soccer players and non-active persons. Moreover, the authors divided the soccer players into four groups, depending on their playing po-

Andreas Konrad · Markus Tilp

Institute of Sports Science, University of Graz, Graz, Austria

\title{
Muscle and tendon tissue properties of competitive soccer goalkeepers and midfielders
}

\author{
A pilot study
}

sitions (defenders, midfielders, wingers, forwards). No difference in MVC torque and muscle-tendon stiffness between all five groups (four athlete groups and one group with non-active persons) was found. However, in their study, Faria et al. (2013) did not include goalkeepers, who have very specific requirements in their playing position. Goalkeepers, however, are an essential part of a soccer team and should therefore be considered. Compared to field players, the movement of a goalkeeper during defending situations is explosive and requires capacity to jump (Knoop, Fernandez-Fernandez, \& Ferrauti, 2013). Field players (especially midfielders), however, have a requirement for endurance. During a soccer game, the average heart rate of a field player is at $80-90 \%$ of its maximum (Hoff, 2005), while one could assume that goalkeepers have lower heart rate values during both training and competition. Midfielders run the most (up to $11.9-12 \mathrm{~km}$ ) compared to all other players (forwards up to $11.2 \mathrm{~km}$; defenders up to $10.6-11.4 \mathrm{~km}$; Di Salvo et al., 2007), whereas goalkeepers run the shortest distance in a soccer game (4km, Gil, Gil, Ruiz, Irazusta, \& Irazusta, 2007). Moreover, midfielders have significantly higher $\mathrm{VO} 2$ max values compared to all other playing positions, while the goalkeepers have the lowest (Najafi, Shakerian, Habibi, Shabani, \& Fatemi, 2015).

To the best of our knowledge, no studies so far have compared the functional (range of motion (RoM), passive resistive torque (PRT), MVC torque, muscle- tendon stiffness) and structural (muscle stiffness, tendon stiffness, muscle thickness, fascicle length, pennation angle) parameters of the lower leg muscles of soccer goalkeepers and midfielders and their less-active peers.

Therefore, the main objective of this study was to determine and compare the functional and structural parameters of the lower leg muscles in soccer goalkeepers, midfielders, and less-active persons (controls).

Due to the findings in the literature, we hypothesized that goalkeepers would demonstrate higher MVC torque values and higher tendon and/or muscle stiffness compared to midfielders and nonactive controls.

\section{Methods}

\section{Experimental design}

A total of 21 participants volunteered in the study. They were assigned to a goalkeeper group $(n=7)$, a midfielder group $(n=7)$, and a control group $(n=7)$. The RoM, PRT, MVC torque, and several parameters of the MTU (muscle thickness, fascicle length, pennation angle, muscle stiffness, passive tendon stiffness) of the gastrocnemius medialis (GM) were determined.

\section{Participants}

Twenty-one healthy male participants (mean $\pm S D ; \quad 22.5 \pm 2.4$ years, 179.0 $\pm 6.1 \mathrm{~cm}, 75.4 \pm 10.0 \mathrm{~kg}$ ) volunteered in this study. The goalkeepers, midfielders, 
and controls performed a training volume of (mean $\pm \mathrm{SD}$, range) $10.7 \pm 1.3 \mathrm{~h}$, $9-12 \mathrm{~h} ; 11.7 \pm 0.8 \mathrm{~h}, 10-12 \mathrm{~h} ;$ and 2.3 $\pm 1.9 \mathrm{~h}, 0-4 \mathrm{~h}$, per week, respectively. The goalkeepers (GK) and the midfielders (MF) were competitive soccer players who played in the Austrian second (GK: 2; MF: 5), third (GK: 4; MF: 1), and fourth (GK: 1; MF: 1) leagues. Each subject was informed about the testing procedure, but not about our hypotheses, and they each gave written consent to participate in the study. Written handouts and personal interviews were used to inform participants about all involved procedures. Participants with a history of lower leg injuries were excluded. Furthermore, subjects of the control group had to be between 18 and 25 years old and not participate in a training regime. Only soccer players from the second to the fourth Austrian soccer league were included in this study. The Ethical Committee of the University of Graz approved the study.

\section{Measures}

To ensure a high scientific standard, all measurements were undertaken by the same investigator. The temperature in the laboratory was kept constant at around $20.5^{\circ} \mathrm{C}$. Measurements were performed without any warm-up and in the following order: 1. RoM (1-min break); 2. PRT (1-min break); 3. MVC.

\section{Range of motion measurement}

To determine the range of motion (RoM), an isokinetic dynamometer (CON-TREX MJ, CMV AG, Duebendorf, Switzerland) was used, and the standard setup for ankle joint movement of the dynamometer was individually adjusted. Participants were seated with a hip joint angle of $110^{\circ}$ and their knee was fully extended on the dynamometer. Moreover, participants were secured with a strap on the upper body to exclude any evasive movement. The foot was fixed barefooted with a strap to the foot plate of the dynamometer, and the estimated ankle joint center was carefully aligned with the axis of the dynamometer to avoid any heel displacement. Moreover, the upper leg was fixed with a strap to avoid any movement of the knee. Par- ticipants were first moved to the neutral ankle joint position in the dynamometer $\left(90^{\circ}\right)$. They were then asked to regulate the motor of the dynamometer with a remote control to get into a dorsiflexion (stretching) position until the point of discomfort was reached. The difference between the maximum dorsiflexion and the neutral position was defined as the dorsiflexion RoM.

\section{Passive resistive torque measurement}

During passive resistive torque (PRT) measurement, the dynamometer moved the ankle joint from a $10^{\circ}$ plantar flexion to the individual maximum dorsiflexion RoM which was previously determined in the RoM measurement. During pilot measurements, we recognized a conditioning effect during the first two passive movements, similar to the active conditioning reported by Maganaris (2003). Therefore, the ankle joint was moved passively for three cycles and measurements were taken during the third cycle to minimize bias due to conditioning effects. Similar to the studies by Kubo, Kanehisa, and Fukunaga (2002) and Mahieu, Cools, De Wilde, Boon, and Witvrouw (2009), the velocity of the dynamometer was set at $5 \%$ s to exclude any reflexive muscle activity. Participants were asked to relax during the measurements.

\section{Maximum voluntary contraction measurement}

Maximum voluntary contraction (MVC) measurement was performed with the dynamometer at a neutral ankle position $\left(90^{\circ}\right)$. Participants were instructed to perform three isometric MVCs of the plantar flexors for $5 \mathrm{~s}$, with rest periods of at least $1 \mathrm{~min}$ between the measurements to avoid any fatigue. The attempt with the highest MVC torque value was taken for further analysis.

\section{Electromyography}

Muscular activity was monitored by Electromyography (EMG; myon 320, myon AG, Zurich, Switzerland) during PRT and MVC measurements. After standard skin preparation surface electrodes (Blue Sensor N, Ambu A/S, Ballerup, Denmark) were placed on the muscle bellies of the GM and the tibialis anterior according to SENIAM recommendations (Hermens et al., 1999). In the PRT measurements, the raw EMG (normalized to plantar flexor MVC) was monitored post hoc to ensure that the subject was relaxed, i.e., did not show EMG activity exceeding 5\% of MVC (Gajdosik, Vander Linden, McNair, Williams, \& Riggin, 2005; Kato, Kanehisa, Fukunaga, \& Kawakami, 2010). The sample rate was $2000 \mathrm{~Hz}$. The EMG signals were highpass filtered $(10 \mathrm{~Hz}$, Butterworth) and root-mean-square (RMS, $50 \mathrm{~ms}$ window) values were calculated.

\section{Measurement of elongation of the muscle-tendon structures}

A real-time ultrasound apparatus (mylab 60, Esaote S.p.A., Genova, Italy) with a 10-cm B-mode linear-array probe (LA 923, Esaote S.p.A., Genova, Italy) was used to obtain longitudinal ultrasound images of the GM.

During the PRT measurements, the ultrasound probe was placed on the distal end of the GM (see Fig. 2 Konrad \& Tilp, 2014a, 2014b), where the muscle is connected to the Achilles tendon, i.e., the muscle tendon junction (MT); Kato et al., 2010). The ultrasound probe was covered by a custom-built Styrofoam block and secured with elastic bands to prevent any displacement of the probe. During a previous study (Stafilidis \& Tilp, 2015), we confirmed that this kind of fixation of the ultrasound probe did not lead to any unwanted shifts of the probe during the measurement. To determine the muscle displacement during PRT measurement, the echoes of the MTJ in the ultrasound videos were manually tracked (Kato et al., 2010). Similar to the approach used by other authors (Morse, Degens, Seynnes, Maganaris, \& Jones, 2008; Kato et al., 2010), the cadaveric regression model of Grieve, Gavanagh, and Pheasant (1978) was used to obtain the length changes of the MTU of the GM during passive movements. The difference between the overall MTU length change and the displacement of the muscle (determined by MTJ displacement) was defined as the tendon displacement.

Prior to the RoM measurement, the muscle thickness and the length of the 
GM fascicle and its pennation angle with the deep aponeurosis were determined from the ultrasound videos at a neutral position of the ankle joint $\left(90^{\circ}\right)$. The ultrasound probe was placed at $50 \%$ of the GM muscle length (Morse et al., 2008).

The ultrasound images were recorded at $25 \mathrm{~Hz}$, with an image depth resolution of $74 \mathrm{~mm}$ ( 65 pixels $\hat{=} 1 \mathrm{~cm}$; Konrad \& Tilp, 2014a, 2014b; Konrad, Gad, \& Tilp, 2015). During PRT measurements, the videos were synchronized with the other data with a custom-built manual trigger. The videos were cut and digitized in VirtualDub open-source software (version 1.6.19, www.virtual dub.org) and analyzed in ImageJ open-source software (version $1.44 \mathrm{p}$, National Institutes of Health, Bethesda, MD, USA).

Each video was measured by two investigators, and the mean values of both measurements were used for further analysis of the muscle-tendon structure. In total three investigators were participants of this study. Except for the principal investigator, the two other investigators were not informed of the hypotheses of the study or the group allocation and participants' names. During the analysis of the PRT measurement, every fifth frame was measured by the investigators, corresponding to a time resolution of $0.2 \mathrm{~s}$.

\section{Calculation of muscle-tendon force, passive muscle-tendon stiffness, and muscle-tendon stiffness}

The muscle force of the GM was estimated by multiplying the measured torque by the relative contribution of the physiological cross-sectional area $(18 \%)$ of the GM within the plantar flexor muscles (Kubo et al., 2002; Mahieu et al., 2009), and dividing by the moment arm of the triceps surae muscle, which was individually measured by tape measure as the distance between the malleolus lateralis and the Achilles tendon at rest at neutral ankle position $\left(90^{\circ}\right.$, Konrad \& Tilp, 2014a, 2014b; Konrad et al., 2015). The mean value of the MA was $4.5 \mathrm{~cm}$ and the range was $4.0-5.0 \mathrm{~cm}$.

Passive tendon stiffness, muscle stiffness, and muscle-tendon stiffness were calculated as the change in the passive force produced from the neutral ankle

Ger J Exerc Sport Res 2018 · 48:245-251 https://doi.org/10.1007/s12662-018-0510-7

(c) The Author(s) 2018.

\section{A. Konrad · M. Tilp \\ Muscle and tendon tissue properties of competitive soccer goalkeepers and midfielders. A pilot study}

\section{Abstract}

The purpose of this pilot study was to investigate the effect of playing-position-dependent training routines in soccer on the various muscle-tendon parameters. We hypothesized that there would be differences in such parameters between competitive goalkeepers and midfielders. According to their playing position, 21 healthy volunteers were assigned to goalkeeper $(n=7)$, midfielder $(n=7)$, and control $(n=7)$ groups. To investigate the muscle-tendon parameters, we determined the maximum dorsiflexion range of motion and the corresponding muscle thickness, fascicle length, and pennation angle of the gastrocnemius medialis. Passive resistive torque and maximum voluntary contraction were measured with a dynamometer. Observation of muscle-tendon junction displacement with ultrasound allowed us to determine length changes in the tendon and muscle, respectively, and hence to calculate stiffness. There was no significant difference in range of motion, passive resistive torque, muscle-tendon stiffness, and the examined structural parameters (e.g., tendon stiffness) between the three groups. However, we found a significant difference in maximum voluntary contraction torque between the goalkeepers and midfielders vs. the controls, but not between the athlete groups. Habitual training leads to higher muscle strength in soccer players compared to less active persons. However, soccer training does not lead to specific muscle and tendon architecture adaptations according to playing position or when compared to less active persons.

\section{Keywords}

Football · Stiffness · Ultrasound · Passive resistive torque $\cdot$ Maximum voluntary contraction

\section{Eigenschaften von Muskel- und Sehnengewebe bei an Fußballwettbewerben teilnehmenden Torhütern und Mittelfeldspielern. Eine Pilotstudie}

\section{Zusammenfassung}

Ziel der vorliegenden Pilotstudie war es, die Wirkung spielpositionsabhängiger Fußballtrainingsprogramme auf die verschiedenen Muskel-Sehnen-Parameter zu untersuchen. Postuliert wurde, dass sich Torhüter und Mittelfeldspieler, die Wettkampfsport betreiben, in derartigen Parametern unterscheiden. Gemäß ihrer Spielposition wurden 21 gesunde freiwillige Teilnehmer Gruppen zugeordnet: Torhüter ( $n=7)$, Mittelfeldspieler $(n=7)$ und einer Kontrollgruppe $(n=7)$. Für die Untersuchung der MuskelSehnen-Parameter wurden der maximale Bewegungsumfang der Dorsalflexion sowie die dazugehörige Muskeldicke, Faszikellänge und der Fiederungswinkel des Musculus gastrocnemius medialis bestimmt. Das passive Drehmoment und die Maximalkraft wurden mithilfe eines Dynamometers gemessen. Die sonographische Beobachtung der Verlagerung des Muskel-SehnenÜbergangs ermöglichte eine Bestimmung von Längenänderungen der Sehne bzw. des Muskels und damit die Berechnung der Steifigkeit. Zwischen den drei Gruppen fanden sich keine signifikanten Unterschiede im Bewegungsumfang, dem passiven Drehmoment, der Muskel-Sehnen-Steifigkeit und den untersuchten Strukturparametern (beispielsweise Sehnensteifigkeit). Ein signifikanter Unterschied bestand jedoch im Maximalkraftdrehmoment zwischen Torhütern/Mittelfeldspielern und der Kontrollgruppe, nicht aber zwischen den beiden sportlich aktiven Gruppen. Ständiges Training führt zu einer höheren Muskelkraft bei Fußballspielern im Vergleich zu weniger aktiven Personen. Fußballtraining bedingt aber keine spezifischen Anpassungen der Muskel- und Sehnenstruktur in Abhängigkeit von der Spielposition oder im Vergleich zu weniger aktiven Personen.

Schlüsselwörter

Fußball · Steifigkeit · Ultraschall · Passives Drehmoment $\cdot$ Maximalkraft 
Table 1 (A) Results of maximum dorsiflexion RoM, as well as muscle thickness, fascicle length, and pennation angle during RoM measurement. (B) Results of PRT, passive tendon stiffness, muscle stiffness, and muscle-tendon stiffness during passive measurements. (C) Results of MVC torque Results

\begin{tabular}{|c|c|c|c|c|c|c|c|c|}
\hline \multirow[b]{2}{*}{ A } & \multirow[b]{2}{*}{ Range of motion $\left({ }^{\circ}\right)$} & \multicolumn{2}{|c|}{ Goalkeepers } & \multicolumn{2}{|c|}{ Midfielders } & \multicolumn{2}{|c|}{ Controls } & \multirow{2}{*}{$\begin{array}{l}\boldsymbol{P} \\
0.48\end{array}$} \\
\hline & & 25.1 & $(9.2)$ & 26.9 & (6.3) & 22.1 & (5.9) & \\
\hline & Muscle thickness (cm) & 1.9 & $(0.2)$ & 1.9 & $(0.2)$ & 1.7 & $(0.3)$ & 0.11 \\
\hline & Fascicle length $(\mathrm{cm})$ & 5.1 & $(0.3)$ & 4.9 & $(0.8)$ & 4.8 & $(0.9)$ & 0.75 \\
\hline & Pennation angle $\left({ }^{\circ}\right)$ & 22.8 & (3.6) & 23.5 & $(2.4)$ & 20.3 & $(1.2)$ & 0.08 \\
\hline \multirow[t]{4}{*}{ B } & $\begin{array}{l}\text { Passive resistive torque } \\
(\mathrm{Nm})\end{array}$ & 34.2 & $(20.0)$ & 31.7 & $(11.7)$ & 18.9 & $(10.5)$ & 0.18 \\
\hline & $\begin{array}{l}\text { Passive tendon stiffness } \\
(\mathrm{N} / \mathrm{mm})\end{array}$ & 23.6 & (8.6) & 20.6 & $(4.4)$ & 23.8 & $(8.5)$ & 0.68 \\
\hline & Muscle stiffness (N/mm) & 9.9 & $(5.2)$ & 9.0 & (3.3) & 5.7 & $(2.7)$ & 0.17 \\
\hline & $\begin{array}{l}\text { Muscle-tendon stiffness } \\
\left(\mathrm{Nm} /{ }^{\circ}\right)\end{array}$ & 1.2 & $(0.5)$ & 1.2 & $(0.3)$ & 0.8 & $(0.3)$ & 0.11 \\
\hline $\mathrm{C}$ & MVC torque (Nm) & 156.6 & (34.4)\# & 160.6 & (27.5)\# & 103.9 & $(36.0)$ & $0.01^{*}$ \\
\hline
\end{tabular}

position $\left(90^{\circ}\right)$ to maximum dorsiflexion divided by the change of the related tendon length, muscle length, and joint angle, respectively.

\section{Statistical analyses}

SPSS (version 20.0, SPSS Inc., Chicago, IL, USA) was used for all the statistical analyses. To determine the interrater reliability of the muscle-tendon displacement measurements, intraclass correlation coefficients (ICCs) were used. A Kolmogorov-Smirnov test was used to verify the normal distribution of all the parameters. One-way analysis of variance (ANOVA) with post hoc Bonferroni tests was performed to test if the mean values of the groups were different in any parameter. The linearity of the tendon, muscle, and muscle-tendon stiffness calculations was controlled with Pearson correlation coefficients. The effect size (d) was calculated by dividing the difference of means by its common standard deviation (Cohen, 1988). Following to the suggestions of Cohen (1988) we defined 0.2, 0.5, and 0.8 as small, medium, and large effect, respectively. The statistical power and power analysis was calculated with the open source software $G^{\star}$ Power. An alpha level of $P=0.05$ was defined for the statistical significance of all the tests.

\section{Results}

\section{Anthropometrics and training volume}

The participants of all three groups (goalkeepers, midfielders, controls) did not show a significant difference in body height (mean $\pm \mathrm{SD}$; goalkeepers: $\quad 182.0 \pm 3.2 \mathrm{~cm}$, midfielders: $178.6 \pm 3.2 \mathrm{~cm}$, controls: $176.6 \pm 6.8 \mathrm{~cm}$ ), body mass (mean $\pm \mathrm{SD}$; goalkeepers: $78.5 \pm 4.6 \mathrm{~kg}$, midfielders: $74.7 \pm 4.6 \mathrm{~cm}$, controls: $72.9 \pm 15.8 \mathrm{~cm}$ ), and age (mean $\pm \mathrm{SD}$; goalkeepers: $23.2 \pm 2.4$ years, midfielders: $22.8 \pm 2.4$ years, controls: $21.5 \pm 2.9$ years). However, there was a significant difference in training volume between the goalkeepers (mean \pm $\mathrm{SD} ; 10.7 \pm 1.3 \mathrm{~h}$ ) and the controls (mean $\pm \mathrm{SD} ; 2.3 \pm 1.9 \mathrm{~h}$ ), and also between the midfielders (mean $\pm \mathrm{SD} ; 11.7 \pm 0.8 \mathrm{~h}$ ) and the controls. Moreover, there was no significant difference in training volume between the goalkeepers and the midfielders.

\section{Data exclusion and measurement quality}

One subject of the controls had to be excluded from the passive measurement due to the poor quality of the ultrasound video. In this low-quality ultrasound video, the MTJ was not identifiable with the necessary precision.

The mean ICCs of the interrater test of the ultrasound video analysis were 0.96 , $0.98,0.95,0.96$, and 0.95 for muscle thickness, pennation angle, and fascicle length during the RoM measurement, and MTJ displacement during PRT measurement, respectively. Values above 0.90 are classified as high (Vincent \& Weir, 2012).

The mean values of the Pearson correlation coefficients at the linear regression were $0.92,0.96$, and 0.97 , with all $P<0.05$, for passive tendon stiffness, muscle stiffness, and muscle-tendon stiffness, respectively.

\section{Range of motion and the related structural muscle parameters}

There was no significant difference between the three groups (goalkeepers, midfielders, and controls) in RoM, muscle thickness, fascicle length, and pennation angle (see $\bullet$ Table 1 , section A).

\section{Passive resistive torque and the related structural muscle-tendon parameters}

No significant differences could be detected in PRT, passive tendon stiffness, muscle stiffness, and muscle-tendon stiffness between the goalkeepers, midfielders, and the controls (see • Table 1, section $\mathrm{B}$ ).

\section{Maximum voluntary contraction}

The one-way ANOVA showed a significant difference in MVC torque. The post hoc Bonferroni tests revealed a difference in MVC torque between the goalkeepers and the controls $(P=0.02)$, and a difference between the midfielders and the controls $(P=0.01)$. However, there was no significant difference in MVC torque between the goalkeepers and the midfielders (see - Table 1, section C).

\section{Discussion and conclusions}

This pilot study compared the muscle and tendon tissue properties of competitive soccer goalkeepers, midfielders, and less-active controls. No significant dif- 
Table 2 Differences, effect size (ES), and power of any parameter of the goalkeepers and midfielders, of the goalkeepers and controls, and of the midfielders and controls

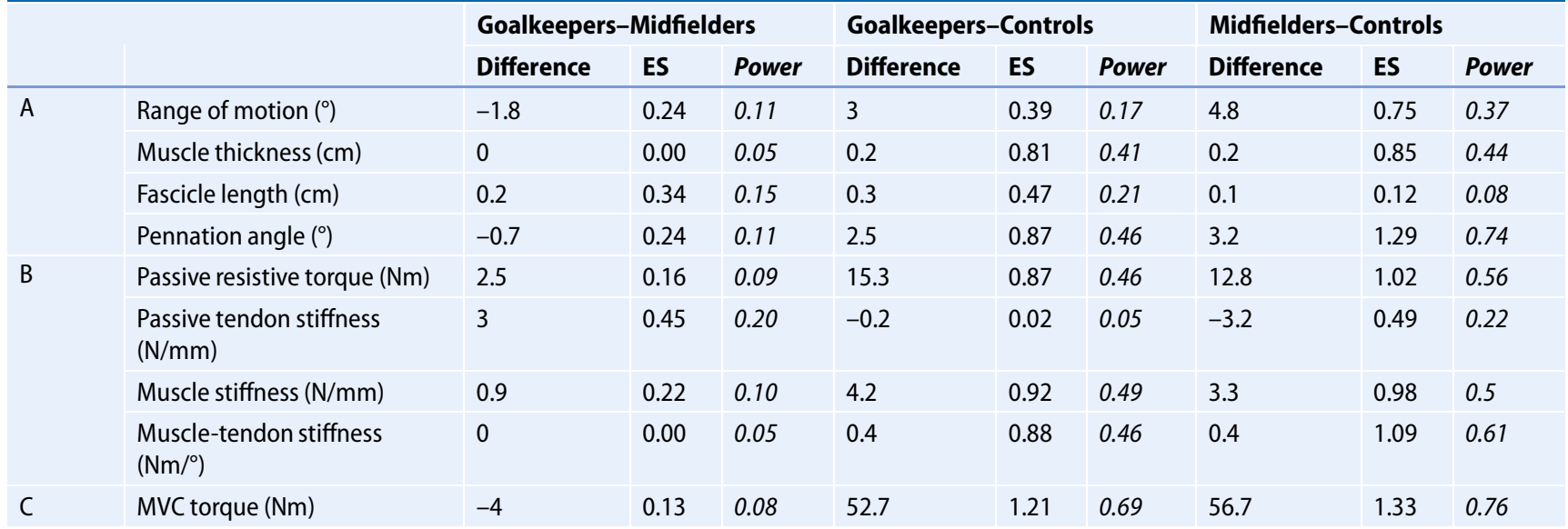

ferences were found in the functional parameters of RoM, PRT, and muscletendon stiffness, and several structural parameters, including muscle and tendon stiffness, muscle thickness, fascicle length, and pennation angle. However, the MVC torque was significantly higher in the goalkeeper and midfielder groups compared to the control group. Though, since this is a pilot study with a small sample size further studies are necessary to strengthen the results of the present study.

Higher MVC torque values in athletes (sprinters and endurance athletes) compared to non-active persons have also been reported by Arampatzis et al. (2007). In their study, it was found that the sprinters also had significantly higher MVC torque values $(154.6 \mathrm{Nm})$ than the endurance athletes $(126.3 \mathrm{Nm})$. Stenroth et al. (2015) found a tendency for higher MVC torque in older sprinters (153 Nm) compared to older endurance athletes (age of both groups around 74 years; $116 \mathrm{Nm})$. In the present study, both the goalkeepers (156.6 Nm) and the midfielders $(160.6 \mathrm{Nm})$ had similar torque values to the sprinters in the study of Arampatzis et al. (2007). One could therefore assume that training for midfielders and goalkeepers leads to a similar development of strength in the plantar flexor muscles. In our first hypothesis, we expected higher MVC torque values in the more sprinter-like goalkeeper group compared to the more endurance-like midfielder group. Surprisingly, this was not confirmed by our results. One could therefore assume that training for midfielders and goalkeepers leads to similar development of strength in the plantar flexor muscles. However, the higher volumes of activity lead to higher maximum isometric torque values. This was confirmed by the significant positive correlation $(r=0.58 ; P=0.01)$ between the training volume and MVC torque values in our data. Similar to the present study, Faria et al. (2013) found no differences in MVC torque between several playing positions (defenders, midfielders, wingers, forwards, non-players) in their soccer study. Due to the results of the study of Faria et al. (2013) and our study, one could deduce that the specific training loads of the playing positions in soccer seem to affect the adaptation of the MTU in a similar way.

Regarding further parameters of the MTU, Arampatzis et al. (2007), in a study of active track and field athletes, but not Stenroth et al. (2015), in a study of older athletes, found stiffer tendons in the sprinter group than in the endurance and non-active groups. Due to the explosive characteristic of goalkeeper movements (similar to the sprinters in the study of Arampatzis et al. (2007)), we expected that goalkeepers would have stiffer tendons and/or muscles than midfielders and the controls. However, we did not find any difference in passive tendon stiffness, muscle stiffness, muscle thickness, pennation angle, or fascicle length between the three groups (goal- keepers, midfielders, controls). This is in contrast to some results from the literature which showed that training and other chronic processes led to specific adaptations of the MTU. Several studies found structural adaptations due to endurance training habits in the muscle cross sectional area (Stenroth et al., 2015), fascicle length (Oda et al., 2015), tendon length (Sano et al., 2013), and tendon stiffness (Oda et al., 2013; Kunimasa et al., 2015). Moreover, Reeves, Narici, and Maganaris (2003) determined that repeated strength training increased patella tendon stiffness. It was also found that repeated isometric strength training increased MVC torque and muscle volume in a study by Kubo et al. (2009). Furthermore, Foure, Nordez, and Cornu (2012) found higher muscle stiffness and a tendency for increased muscle-tendon stiffness $(P=0.09)$ following a plyometric training program over 14 weeks. Csapo, Maganaris, Seynnes, and Narici (2010) showed higher Achilles tendon cross-sectional area and stiffness and shorter fascicle lengths following the chronic use of high heels. Soccer training, especially in the preparation phase, also consists of strength training and plyometric training. With regard to the findings in the literature, one could therefore assume that these training regimes lead to higher tendon and muscle stiffness. In general, training regimen of goalkeepers and midfielders are different. Therefore, one could assume that these groups will 
have different muscle and tendon function and structure.

The lack of significant differences in structural parameters between the goalkeepers and the midfielders but also between the athletes groups and the non-active controls could possibly be explained by the small sample size of the pilot study. Therefore, we determined the effect size and statistical power of all the parameters between the three groups (see • Table 2). While effect sizes were quite high between athletes and controls (mean 0.77, range 0.02-1.33) they were rather small between goalkeepers and midfielders (mean 0.19, range $0.00-0.45)$. Statistical power was rather low $(<0.8)$ in all our results, indicating that possible differences between the groups might be overlooked. At one hand, it appears that the amount of subjects was too small to detect significant differences between athletes and controls. An a priori power analysis for two independent means $(\mathrm{d}=0.8$; power $=0.8 ; \quad \alpha=0.05)$ has shown that 21 subjects for each group would have been appropriate. On the other hand small effect sizes indicate that there is no physiological meaningful difference between the athletes group. This is underlined by a respective power analysis with the observed difference between the athlete groups $(\mathrm{d}=0.19$, power $=0.8$, $\alpha=0.05$ ) which produced a necessary sample size of 344 for each group which cannot be realized. Hence, we are confident about the main conclusion (no differences between the athlete groups) of the present study.

Concerning the lack in significant differences (except MVC torque) between the athletes and the non-active controls, one possible explanation could be in the higher (but not significantly so) RoMs in the goalkeepers $\left(25.1^{\circ}\right)$ and midfielders $\left(26.9^{\circ}\right)$ compared to the controls $\left(22.1^{\circ}\right)$. It was reported in some studies (Mahieu et al., 2007; Konrad et al., 2015) that alongside with increased RoM tendon stiffness decreased following a stretching regime. It is possible that the frequent stretching by the goalkeepers and midfielders led to a similar stiffness to the controls. Furthermore, some of the 'nonactive' persons actually undertook up to
$4 \mathrm{~h}$ of activity a week, which might have already led to adaptations of the MTU.

There are some limitations to this study. First, the sample size of the groups was small, and this may have influenced the results. However, power analysis (results not presented) has shown that the main outcome of the study would have been the same with a larger number of participants. Thus, we believe that this pilot study could provide important information for future studies on this topic. Second, the persons taking the measurements were not all blind to the intervention. Therefore, a bias in the results cannot be completely excluded, although the interrater reliability was excellent (mean ICC: 0.95-0.98). Third, the method of measuring the moment arm of the ankle joint in vivo was quite simple. However, the values obtained in this study were very similar to others obtained using magnetic resonance imaging data (Rugg, Gregor, Mandelbaum, \& Chiu, 1990) or ultrasound (Lee \& Piazza, 2009). Fourth, according to Kubo et al. (2002) and Mahieu et al. (2007, 2009), the GM muscle force was estimated assuming that it comprises $18 \%$ of the whole plantar flexors muscle group. This might be a rough estimation in some subjects. Fifth, although we monitored the measurements carefully, we cannot rule out small changes in the axis of the ankle joint in relation to the dynamometer axis due to heel displacement. This would have led to differences between the measured ankle joint angles/moments and real ankle joint angles/moments during measurements (Arampatzis et al., 2005a). An implication of this limitation would be erroneous assessments of the MTJ displacement (Arampatzis et al., 2005b) during the passive measurements and hence to incorrect estimations of muscle and passive tendon stiffness. However, there is no indication that errors due to both limitations four and five are systematically different in the different subject groups and, therefore, would not significantly affect the general outcome of the study.

In conclusion, this pilot study found no difference in the functional and structural parameters of the MTU between soccer goalkeepers and midfielders. However, there was a significant difference in MVC torque between the athlete groups (goalkeepers and midfielders) and the less-active persons. Further studies should explore possible changes of the MTU over an entire soccer season. Moreover, other types of sports (handball, basketball, volleyball, tennis, etc.) with different requirements should also be investigated in this regard.

\section{Corresponding address}

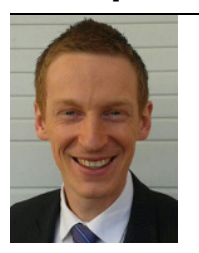

Mag. Dr. A. Konrad, BSc

MSc

Institute of Sports Science, University of Graz

Mozartgasse 14, $8010 \mathrm{Graz}$,

Austria

andreas.konrad@uni-graz.at

Funding. Open access funding provided by University of Graz.

\section{Compliance with ethical guidelines}

Conflict of interest. A. Konrad and M. Tilp declare that they have no competing interests.

All procedures performed in studies involving human participants were in accordance with the ethical standards of the institutional and/or national research committee and with the 1964 Helsinki declaration and its later amendments or comparable ethical standards. Informed consent was obtained from all individual participants included in the study.

Open Access. This article is distributed under the terms of the Creative Commons Attribution 4.0 International License (http://creativecommons.org/licenses/by/ 4.0/), which permits unrestricted use, distribution, and reproduction in any medium, provided you give appropriate credit to the original author(s) and the source, provide a link to the Creative Commons license, and indicate if changes were made.

\section{References}

Arampatzis, A., Morey-Klapsing, G., Karamanidis, K., DeMonte, G., Stafilidis, S., \& Brüggemann, G.P. (2005a). Differences between measured and resultant joint moments during isometric contractions at the ankle joint. Journal of Biomechanics, 38(4), 885-892.

Arampatzis, A., Stafilidis, S., DeMonte, G., Karamanidis, K., Morey-Klapsing, G., \& Brüggemann, G.P. (2005b). Strain and elongation of the human gastrocnemius tendon and aponeurosis during maximal plantarflexion effort. Journal of Biomechanics, 38(4), 833-841.

Arampatzis, A., Karamanidis, K., De Monte, G., Morey-Klapsing, G., \& Stafilidis, S. (2007). 
Mechanical properties of the triceps surae tendon and aponeurosis in relation to intensity of sport activity. Journal of Biomechanics, 40(9), 1946-1952.

Cohen, J. (1988). Statistical power analysis for the behavioral sciences (2nd edn.). Hillsdale: Erlbaum.

Csapo, R., Maganaris, C. N., Seynnes, O. R., \& Narici, M. V. (2010). On muscle, tendon and high heels. The Journal of Experimental Biology, 213(15), 2582-2588.

Faria, A., Gabriel, R., Abrantes, J., Wood, P., \& Moreira, H. (2013). Mechanical properties of the triceps surae: differences between football and nonfootball players. Journal of Sports Sciences, 31(14), 1559-1567.

Fouré, A., Nordez, A., \& Cornu, C. (2012). Effects of plyometric training on passive stiffness of gastrocnemii muscles and Achilles tendon. European Journal of Applied Physiology, 112(8), 2849-2857.

Gajdosik, R.L., Vander Linden, D.W., McNair, P.J., Williams, A.K., \& Riggin, T.J. (2005). Effects of an eight-week stretching program on the passive-elastic properties and function of the calf muscles of older women. Clinical Biomechanics, 20(9), 973-983.

Gil, S.M., Gil, J., Ruiz, F., Irazusta, A., \& Irazusta, J. (2007). Physiological and anthropometric characteristics of young soccer players according to their playing position: relevance for the selection process. The Journal of Strength \& Conditioning Research, 21(2), 438-445.

Grieve, D. W., Gavanagh, P. R., \& Pheasant, S. (1978). Prediction of gastrocnemius length from knee and ankle join posture. In E. Asmussen \& K. Jorgensen (Eds.), Biomechanics, VI-A (pp. 405-412). Baltimore: University Park Press.

Hermens, H.J., Freriks, B., Merletti, R., Stegeman, D., Blok, J., Rau, G., et al. (1999). European recommendations for surface electromyography. Roessingh Research and Development, 8(2), $13-54$.

Hoff, J. (2005). Training and testing physical capacities for elite soccer players. Journal of Sports Sciences 23(6), 573-582.

Kato, E., Kanehisa, H., Fukunaga, T., \& Kawakami, Y. (2010). Changes in ankle joint stiffness due to stretching: the role of tendon elongation of the gastrocnemius muscle. European Journal of Sport Science, 10(2), 111-119.

Knoop, M., Fernandez-Fernandez, J., \& Ferrauti, A. (2013). Evaluation of a specific reaction and action speed test for the soccer goalkeeper. The Journal of Strength \& Conditioning Research, 27(8), 2141-2148.

Konrad, A., \& Tilp, M. (2014a). Increased range of motion after static stretching is not due to changes in muscle and tendon structures. Clinical Biomechanics, 29(6), 636-642.

Konrad, A., \& Tilp, M. (2014b). Effects of ballistic stretching training on the properties of human muscle and tendon structures. Journal of Applied Physiology, 117(1), 29-35.

Konrad, A., Gad, M., \& Tilp, M. (2015). Effect of PNF stretching training on the properties of human muscle and tendon structures. Scandinavian Journal of Medicine \& Science in Sports, 25(3), 346-355.

Kubo, K., Kanehisa, H., \& Fukunaga, T. (2002). Effect of stretching training on the viscoelastic properties of human tendon structures in vivo. Journal of Applied Physiology (Bethesda, Md.: 1985), 92(2), 595-601.
Kubo, K., Ikebukuro, T., Yaeshima, K., Yata, H., Tsunoda, N., \& Kanehisa, H. (2009). Effects of static and dynamic training on the stiffness and blood volume of tendon in vivo. Journal of Applied Physiology, 106(2), 412-417.

Kunimasa, Y., Sano, K., Makino, A., Akiyama, M., Ito, A., \& Komi, P.V. (2015). Characteristics of muscle and tendon mechanical properties for sprinters and swimmers. In A. Radmann, S. Hedenborg \& E. Tsolakidis (Eds.), Malmö: ECSS book of abstracts (p. 127).

Lee, S. S., \& Piazza, S. J. (2009). Built for speed: musculoskeletal structure and sprinting ability. Journal of Experimental Biology, 212(22), 3700-3707.

Maganaris, C. N. (2003). Tendon conditioning: artefact or property? Proceedings of the Royal Society of London B: Biological Sciences, 270(Suppl 1), S39-S42.

Mahieu, N. N., McNair, P., De Muynck, M., Stevens, V., Blanckaert, I., Smits, N., et al. (2007). Effect of static and ballistic stretching on the muscletendon tissue properties. Medicine and Science in Sports and Exercise, 39(3), 494.

Mahieu, N. N., Cools, A., De Wilde, B., Boon, M., \& Witvrouw, E. (2009). Effect of proprioceptive neuromuscular facilitation stretching on the plantar flexor muscle-tendon tissue properties. Scandinavian Journal of Medicine \& Science in Sports, 19(4), 553-560.

Morse, C.I., Degens, H., Seynnes, O. R., Maganaris, C. N., \& Jones, D. A. (2008). The acute effect of stretching on the passive stiffness of the human gastrocnemius muscle tendon unit. The Journal of physiology, 586(1), 97-106.

Najafi, A., Shakerian, S., Habibi, A., Shabani, M., \& Fatemi, R. (2015). The comparison of some anthropometric, body composition indexes and V02max of Ahwazelite soccer players of different playing positions. Pedagogics, psychology, medical-biological problems of physical training and sports. https://doi.org/10.15561/18189172. 2015.0910.

Oda, T., Toyoda, Y., Hisano, T., Kusumoto, K., Kunimasa, Y., Sano, K., \& Ishikawa, M. (2013). Faster distance runners have more compliant Achilles tendons. In N. Balague, C. Torrents, A. Vilanova, J. Cadefau R. Tarrago \& E. Tsolakidis (Eds.), Barcelona: ECSS book of abstracts (pp. 323-324).

Reeves, N.D., Narici, M.V., \& Maganaris, C.N. (2003). Strength training alters the viscoelastic properties of tendons in elderly humans. Muscle \& Nerve, 28(1), 74-81.

Rugg, S. G., Gregor, R. J., Mandelbaum, B. R., \& Chiu, L. (1990). In vivo moment arm calculations at the ankle using magnetic resonance imaging (MRI). Journal of Biomechanics, 23(5), 495-501.

Di Salvo, V., Baron, R., Tschan, H., Calderon Montero, F. J., Bachl, N., \& Pigozzi, F. (2007). Performance characteristics according to playing position in elite soccer. International Journal of Sports Medicine, 28(3), 222.

Sano, K., Ishikawa, M., Nobue, A., Danno, Y., Akiyama, M., Oda, T., et al. (2013). Muscle-tendon interaction and EMG profiles of world class endurance runners during hopping. European Journal of Applied Physiology, 113(6), 1395-1403.

Stafilidis, S., \& Tilp, M. (2015). Effects of short duration static stretching on jump performance, maximum voluntary contraction, and various mechanical and morphological parameters of the muscle-tendon unit of the lower extremities. European Journal of Applied Physiology, 115(3), 607-617.
Stenroth, L., Cronin, N. J., Peltonen, J., Korhonen, M.T., Sipilä, S., \& Finni, T. (2015). Triceps surae muscle-tendon properties in older endurance-and sprint-trained athletes. Journal of Applied Physiology. https://doi.org/10.1152/ japplphysiol.00511.2015.

Vincent, W. J., \& Weir, J. P. (2012). Statistics in kinesiology (4thedn.). Champaign: Human Kinetics. 